\title{
Os usos e a produção de retratos pintados por Pedro Weingärtner (Século XIX e XX)
}

\author{
The uses and production of portraits painted by Pedro Weingärtner (19th and 20th \\ centuries)
}

\author{
Cyanna Missaglia de Fochesatto ${ }^{1}$
}

\begin{abstract}
Resumo
A presente pesquisa tem como objetivo analisar alguns retratos produzidos pelo artista gaúcho Pedro Weingärtner entre os séculos XIX e XX, nas suas idas e vindas entre Brasil e Europa. $\mathrm{O}$ artigo tem a finalidade de compreender a função dos retratos no processo produtivo de Weingärtner para além de questões mercadológicas, mas também entendê-la como uma forma de manutenção dos vínculos e redes sociais, especialmente, em momentos de troca de regime político no Brasil, como no caso da transição da Monarquia para a República. Investiga-se o uso feito pelo artista dos retratos que ele representou, bem como a importância dessa prática pictórica como um meio de demonstrar determinado status social entre elite política e social, seja ela no Brasil ou na Europa.
\end{abstract}

Palavras-chave: Pintura; Retrato; Pedro Weingärtner.

\begin{abstract}
The present research aims to analyze some portraits produced by the gaucho artist Pedro Weingärtner between the 19th and 20th centuries, during his comings and goings between Brazil and Europe. We aim to understand the role of portraits in Weingärtner's production process, in addition to market issues, but also as a way of maintaining social ties and networks, especially at times of political regime change in Brazil, as in the case of Transition from the Monarchy to the Republic. The use made by the artist of the portraits that he represented is investigated, as well as the importance of this pictorial practice as a way to demonstrate certain social status between the political and social elite, be it in Brazil or in Europe.
\end{abstract}

Keywords: Painting; Portrait; Pedro Weingärtner.

\section{Introdução}

Foi entre as muitas vindas ao Brasil que Pedro Weingärtner aproveitava de suas estadias para reforçar ou formar vínculos sociais, pois foi na terra natal que o artista formou suas redes e seus laços de amizade e de trabalho. Portanto, um dos objetivos desta pesquisa reside na compreensão da forma que Weingärtner utilizou a produção de seus retratos como uma estratégia de reafirmar laços e vínculos sociais, bem como ressaltar a importância de seus retratos para os indivíduos retratados.

\footnotetext{
${ }^{1}$ Doutoranda e Mestre em História pela Universidade do Vale do Rio dos Sinos (UNISINOS). Mestre em História pela Universidade do Vale do Rio dos Sinos (UNISINOS).
} 
Entende-se representação nesta pesquisa, conforme Roger Chartier (1990) reitera ao considerá-la como instrumento de análise da história cultural e afirmar que ela pode ser construída pelos interesses dos grupos que as forjam: "Por isso esta investigação sobre as representações supõe-nas como estando sempre colocadas num campo de concorrências e de competições, cujos desafios se enunciam em termos de poder e dominação" (CHARTIER, 1990, p. 17). As pinturas de Weingärtner são locais onde guardam uma memória que representa um determinado grupo social ou toda uma sociedade, por isso, abordamos a memória por meio dos estudos do historiador francês Pierre Nora (1993), no qual ela é vista como um processo vivido em evolução constante e vulnerável a todas manipulações, pois: "A memória é vida, [...] aberta à dialética da lembrança e do esquecimento, inconsciente de suas deformações sucessivas, vulnerável a todos os usos e manipulações, susceptível de longas latências e de repentinas revitalizações" (NORA, 1993, p. 9). As pinturas, aqui analisadas, são espaços de possível manipulação da memória, uma vez que elas constroem narrativas históricas, partindo da construção de diversos elementos que podem ser facilmente manipulados, conforme a intenção da pintura, do pintor, do contexto e de quem encomendou a obra.

Nesse sentido, observa-se que o historiador Michael Baxandall, ao discutir as relações entre o discurso imagético e o verbal na análise de uma obra de arte, atenta para o descompasso desta última em relação à primeira. Pois, a linguagem verbal não estaria apta para dar conta de uma obra visual devido a sua significativa quantidade de informações. A descrição de uma imagem - mesmo que possibilite a sua criação mental - jamais se igualará a obra original, uma vez que tal concepção perpassa por questões pessoais, experiências e vivências do sujeito que faz a leitura. Assim, Baxandall defende que a descrição de uma obra - neste caso, tratamos das pinturas de Pedro Weingärtner são impregnadas pelas impressões pessoais e tendências do expositor. A obra estaria incutida pela leitura pessoal de quem a analisa e, assim, não contemplaria a real intenção da obra. Dentro desta perspectiva, Baxandall afirma que: "Nós não explicamos um quadro: explicamos observações sobre um quadro. Dito de outra forma, somente explicamos um quadro na medida em que o consideramos à luz de uma descrição ou especificação verbal dele" (BAXANDALL, 2006, p. 31).

Pedro Weingärtner foi um pintor gaúcho, nascido em Porto Alegre no ano de 1853 e falecido no mesmo lugar, no ano de 1929. Foi, além de pintor, desenhista e gravador, tendo sua iniciação artística no próprio núcleo familiar. Dominou diversas técnicas pictóricas durante sua carreira. Passou parte da vida transitando entre Brasil e 
Europa, sendo nesta última onde viveu grande parte do tempo. Teve sua formação acadêmica junto com alguns mestres, tais como Delfim Câmara, no Brasil, e Ernest Hildebrand, Theodor Poeckh, entre outros, na Europa (GOMES, 2007). Retratou diversos temas, a exemplo dos gaúchos, das cenas da natureza brasileira e também das paisagens da Europa, dos imigrantes europeus, das cenas da Antiguidade clássica e de demais motivos. Weingärtner gostava de retratar cenas do dia a dia que lhe chamavam a atenção e era muito meticuloso nos detalhes e símbolos retratados nas pinturas.

O artista gaúcho Pedro Weingärtner foi um exímio retratista, tendo elaborado diversos autorretratos. Desenhou familiares, como a mãe, esposa e os irmãos. Além disso, retratou alguns amigos e políticos brasileiros importantes. Executou um quadro de Júlio de Castilhos, de provável cunho positivista, que se destaca pelo tamanho quase real da pintura ${ }^{2}$. Weingärtner foi um homem que transitou entre vários espaços e momentos. Trafegou entre o Novo e o Velho Mundo, o regime monárquico e republicano, os séculos XIX e XX, e, mesmo assim, soube manter uma satisfatória relação com todos nos ambientes por onde passou. A primeira imagem é um exemplo desse dualismo que encontramos tanto na trajetória quanto na arte de Weingärtner, pois ele retrata Júlio de Castilhos, Presidente Constituinte do Rio Grande do Sul, após o fim do regime monárquico, retrata seu amigo Carlos Von Koseritz e D. Pedro II, seu mecenas e quem lhe concedeu a bolsa de estudos na Europa.

O retrato de Júlio de Castilhos, foi elaborado em Roma, sob encomenda do Estado, no ano de 1905. A obra de grande dimensão, intitulada Júlio de Castilhos, Presidente Constituinte de RGS, seria um exemplo da permanência dos laços políticos que Weingärtner manteve no Brasil, mesmo com a troca de regimes, ou seja, com o fim do regime monárquico.

\footnotetext{
${ }^{2}$ Buscando compreender o que se considera uma pintura positivista: "No campo da arte, o positivismo estipulava que as obras deveriam ter sempre um caráter científico, realista e detalhista, pois deviam basear-se na observação dos fatos, além de possuir uma forte temática política e moral" (BORGES; BOTELHO, 2012, p. 2). Embora não possamos considerar Weingärtner um pintor positivista, podemos observar na pintura de Júlio de Castilhos alguns elementos que se enquadram em tal padrão.
} 


\section{Figura 1 - Júlio de Castilhos}

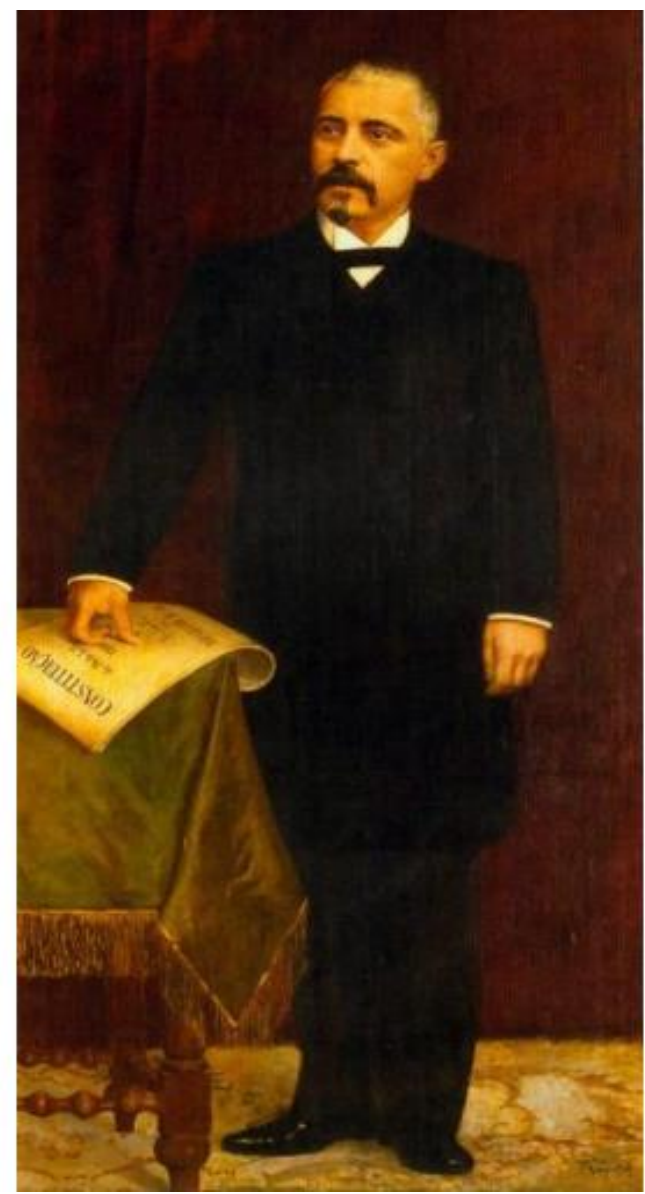

Fonte: (WEINGÄRTNER, 1905). ${ }^{3}$

Nesta imagem, observa-se um homem de postura firme e ereto, com bastante serenidade na expressão, vestindo uma roupa elegante e de cor escura. Foi retratado em um ambiente interno com um carpete luxuoso ao lado de uma mesa de escrivaninha coberta por um tecido verde fino com franjas. As cores claras destacam o rosto e os elementos do espaço interno retratados e diferenciam-se da seriedade do preto das vestes de Júlio de Castilhos que centralizam a representação. Mas o principal detalhe da tela é carta da Constituição do Estado do Rio Grande do Sul, repousada sob a mão direita do política e onde se lê claramente a palavra "Constituição". Esse simbolismo busca transmitir a estabilidade e a importância desse documento. Júlio de Castilhos foi retratado em seu exercício no cargo público. Essa imagem evidencia a intenção de uma representação de poder e da importância simbólica da Constituição. Ruth Sprung Tarasantch (2009) afirma que: "Sob encomenda do governo, Weingärtner pintou em

\footnotetext{
${ }^{3}$ WEINGÄRTNER, Pedro. Júlio de Castilhos, Presidente Constituinte do RGS, 1905, Roma. Óleo sobre tela, 240 x $140 \mathrm{~cm}$. Acervo da Assembleia Legislativa do Estado do RS, Porto Alegre, RS.
} 
Roma, em 1905, um quadro de grandes dimensões retratando o primeiro Presidente da Constituinte do Rio Grande do Sul, Júlio de Castilhos" (TARASANTCHI, 2009, p. 159).

Pedro Weingärtner teria utilizado as fotografias tanto para retratar Júlio de Castilhos como Dom Pedro II, pois elas tornaram-se elementos bastante comuns na elaboração de pinturas no século XIX e eram mais práticas para aqueles pintores que moravam no exterior e retornavam à terra natal para elaborar obras, não sendo mais essencial que o retratado passasse horas posando para o pintor. Assim, existia uma relação muito importante no século XIX entre a pintura e a fotografia. Weingärtner utilizou muito a fotografia na elaboração de diversas pinturas, uma vez que vinha ao Brasil buscar inspiração e novos motivos para as suas telas. Quando algo lhe chamava a atenção, elaborava rápidos rascunhos ou tirava fotos, as quais levava ao seu ateliê em Roma e reproduzia-as em suas pinturas, como no caso da homenagem póstuma a Júlio de Castilhos e o retrato da estátua de D. Pedro II. Sobre o gênero dos retratos no Brasil, é possível afirmar que ele:

[...] sofreu uma influência crescente da fotografia ao longo do século XIX e início do século XX. Essa influência propiciou uma associação tão íntima quanto produtiva, particularmente no período dito naturalista, tão notavelmente representado por Pedro Weingärtner (1853-1929). D. Pedro II era um entusiasta da fotografia, tendo adquirido um equipamento para obter daguerreótipos ainda adolescente, introduzindo a técnica no país (FERREIRA; ROSSI, 2013, s/p).

É importante mencionar a relação de Carlos von Koseritz, amigo próximo de Weingärtner e seu vínculo com Júlio de Castilhos, uma vez que ambos eram inimigos políticos e Weingärtner fez retratos para os dois. Koseritz faleceu em 30 de maio de 1890, já Júlio de Castilhos morreu em 24 de outubro de 1903. Quando o artista gaúcho terminou a elaboração do retrato de Júlio, Koseritz já havia falecido, portanto, o retrato não causou danos à amizade entre ele e o pintor brasileiro.

Júlio de Castilhos foi um influente político gaúcho, adepto do pensamento positivista, que, além de ter ajudado na fundação do Partido Republicano no Rio Grande do Sul, participou da primeira elaboração de uma Constituição gaúcha, no ano de 1891 (SILVA, 2011, p. 10 - 11) e, não obstante, foi retratado junto ao documento. Ele possuía uma relação tensa e divergente com Carlos von Koseritz. O que se busca atentar nesse momento é a seguinte questão: como um pintor gaúcho da transição do modelo político do Império para a República, amigo próximo de Koseritz, pintou o retrato imponente de Júlio de Castilhos? Poucas são as evidências que se têm sobre as tendências políticas de 
Weingärtner, pois não existem documentações que traga luz à essas questões. No entanto, a pintura foi feita no ano de 1905, após a morte tanto de Júlio quanto de Koseritz. Ao contrário dos retratos feitos para Koseritz como parte de sua demonstração de afeto e amizade, bem como as imagens que reproduziu para D. Pedro II, ao manifestar a sua gratidão ao Imperador, a relação do pintor com o retrato de Júlio de Castilhos era diferente. A tela foi feita sob encomenda do governo e não por gosto do artista. Tendo Weingärtner sempre mantido uma boa relação com o governo brasileiro, seja no Império ou na República, é possível que, em prol dessa relação, Weingärtner teria aceitado retratar o político nessa encomenda, independentemente de suas próprias posições pessoais. Fica assim a dúvida sobre as dimensões políticas na vida do pintor. $\mathrm{O}$ que se sabe é que tanto o período do Império quanto o da República, pouco alterou a vida de Weingärtner, que soube aliar-se aos grupos "certos" não lhe faltando oportunidade de expor e vender seus trabalhos no Brasil. Obteve sucesso e prestígio em ambos regimes políticos. Weingärtner, antes de ser um homem engajado politicamente, algo que não é passível de comprovação em nenhum momento, foi um homem que soube fazer e manter uma forte relação com a elite social brasileira, sendo ela que lhe propiciou e favoreceu nos trabalhos artísticos a maior parte de tempo.

Antonio Acosta Rodríguez (2000), ao concluir sua pesquisa sobre redes sociais, de forma comparada, traz uma importante reflexão: “[...] no parece arriesgado afirmar que los mecanismos sociales de poder, en el marco de las redes sociales, han existido siempre y que existen actitudes y reacciones de individuos o de grupos en ellas que son muy similares [...]”. (RODRÍGUEZ, 2000, p. 169). Embora ainda considere que: "[...] aunque las excusas para los comportamentos - reales o fictícias - difieran en el tempo" (RODRÍGUEZ, 2000, p. 169). À vista disso, as relações de poder e formação de redes dos pintores aqui estudados apontam que ambos utilizaram de sua profissão como mecanismo para ascensão social, ainda que cada qual de forma diferente. E, nesse caso, tratando-se de negociação de poder nas escalas das redes sociais:

Em qualquer tempo ou espaço, os indivíduos criam e recriam vias de circulação de interações em espaços sociais mais ou menos diversificados. [...] é justamente na interação entre os fluxos de transações e os distintos círculos relacionais que os indivíduos definem suas estratégias e negociam suas posições sociais (COMISSOLI; COSTA, 2014, p. 21).

Segue uma imagem de D. Pedro II que serve como outro exemplo da forma que Pedro Weingärtner elaborou estratégias de negociação de suas relações sociais. A figura, intitulada Estátua de D. Pedro II, sem data, foi elaborada também partindo de 
uma fotografia do Imperador. Essa homenagem feita a D. Pedro II possivelmente ocorreu em função do agradecimento de Weingärtner à figura do monarca pelo financiamento de seus estudos na Europa, visto que, sem a pensão concedida pelo governante, o artista não teria condições de se manter sozinho fora do país. Foi aos 30 anos de idade, em 1883, que Weingärtner enviou uma carta a D. Pedro II solicitando auxílio financeiro para que pudesse prosseguir com seus estudos na Europa. No ano de 1884, esse pedido foi atendido.

Na figura 2, é possível observar uma estátua de D. Pedro II, onde ele aparece sentado em um trono com uma postura bastante casual e relaxada, isso possivelmente por se tratar da representação de uma estátua. O Imperador aparece de pernas cruzadas e segurando o rosto com uma das mãos. Ele olha calmamente para frente. A estátua foi retratada em meio à natureza brasileira - que contrasta a estátua clara com todo o verde que rodeia a tela. Flores coloridas nascem do pé da estátua, sendo que a mesma também carrega um buquê de flores brancas.

Figura 2 - Estátua de D. Pedro II

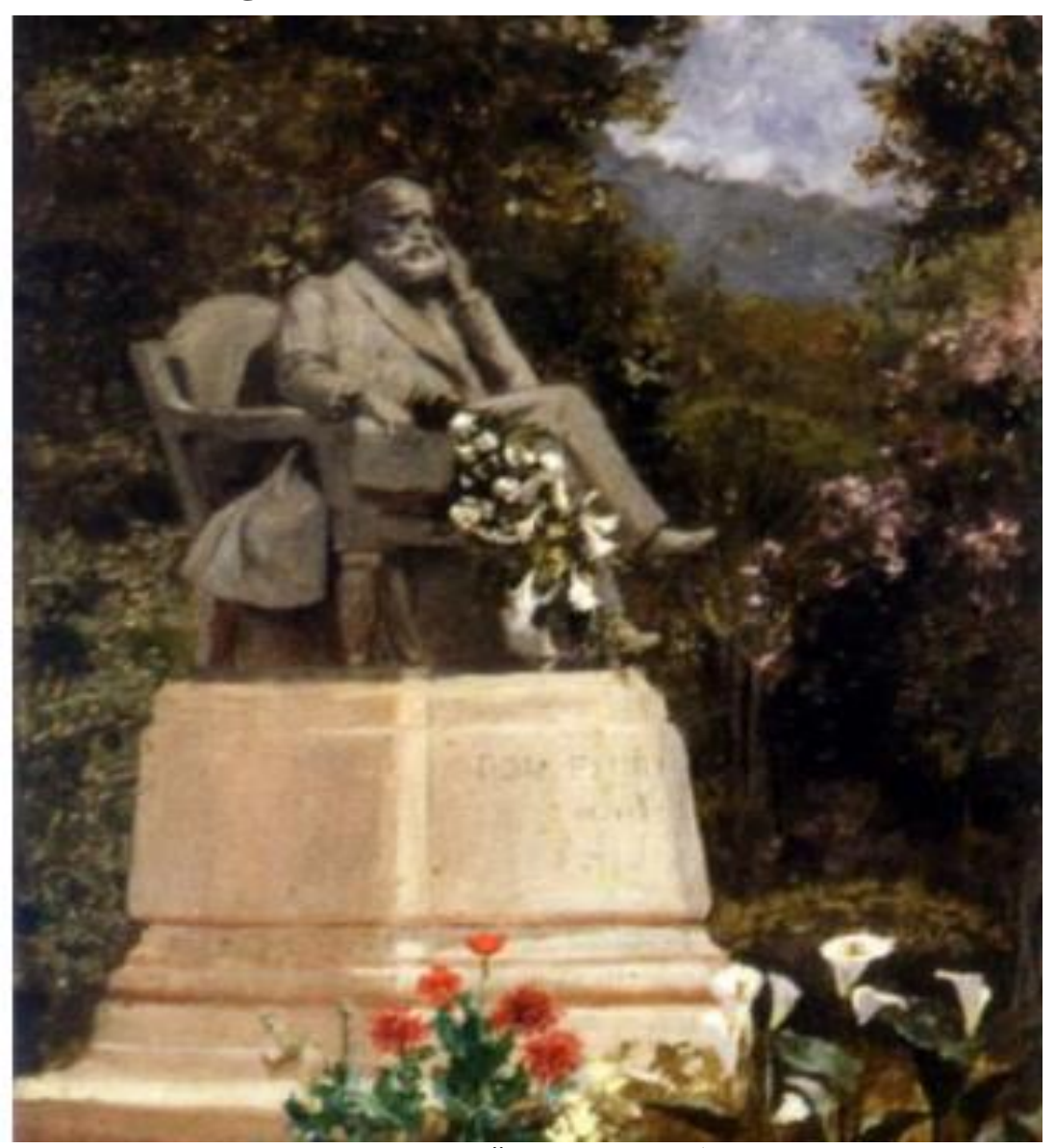

Fonte: (WEINGÄRTNER, s/d). ${ }^{4}$

\footnotetext{
${ }^{4}$ WEINGÄRTNER, Pedro. Estátua de D. Pedro II, sem data. Óleo sobre madeira, 22 x $13 \mathrm{~cm}$. Acervo da Pinacoteca Aplub, Porto Alegre-RS.
} 
Abaixo, seguem duas fotografias que, provavelmente, serviram de suporte para a elaboração da pintura como é possível perceber nas próprias palavras do pintor que serão observadas na sequência.

Figura 3 - Foto de D. Pedro II

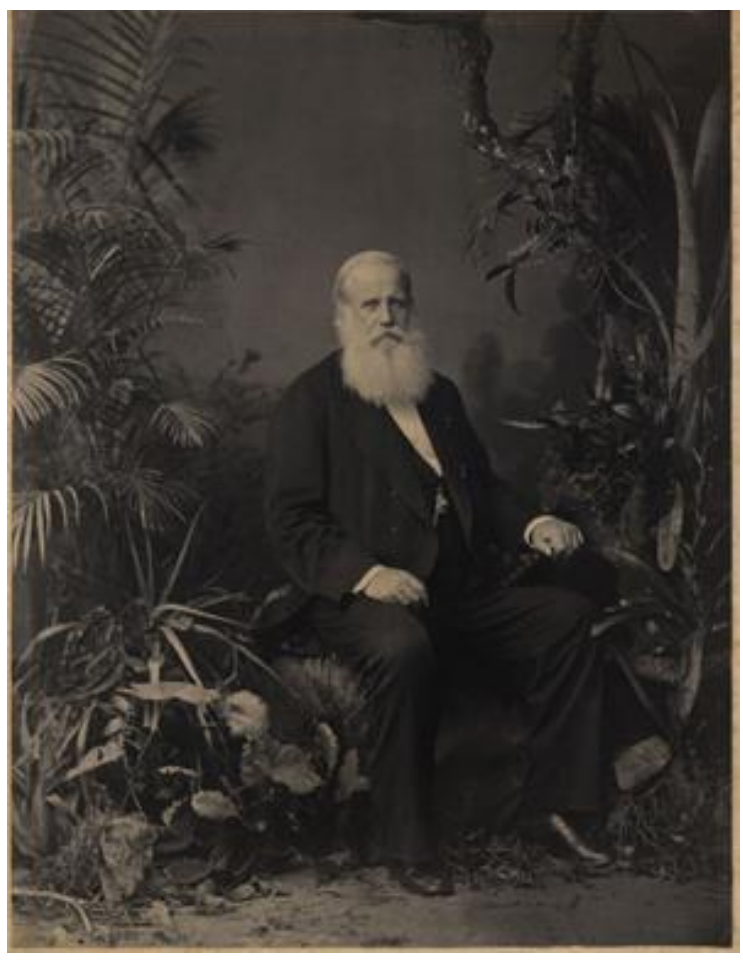

Fonte: (PACHECO, 1883). ${ }^{5}$
Figura 4 - Foto de D. Pedro II

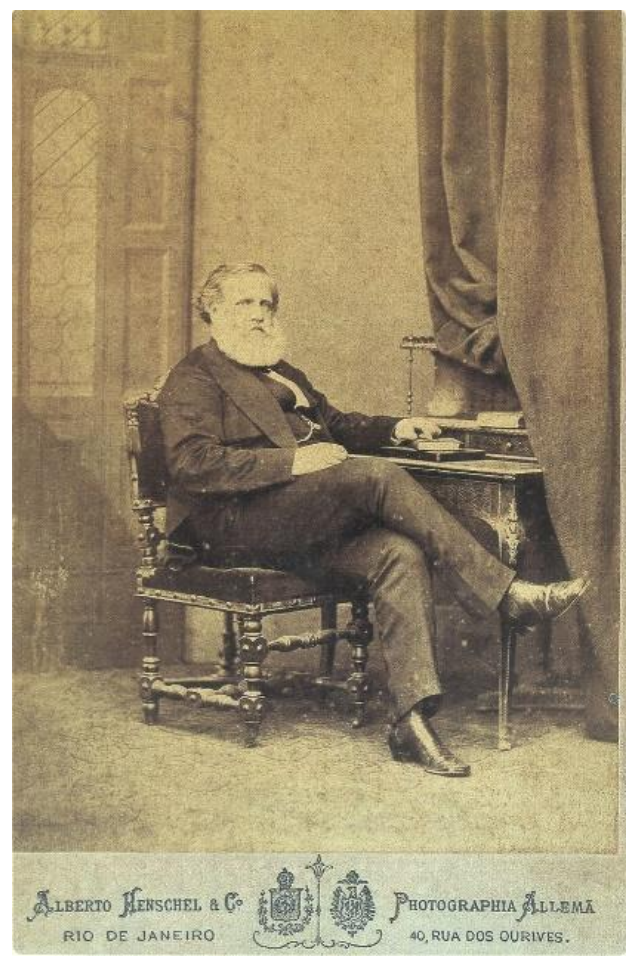

Fonte: (HENSCHEL, 1875). ${ }^{6}$

Ambas fotografias podem ter servido de inspiração, sendo a primeira pelo cenário que em muito se assemelha ao que Weingärtner retratou na estátua do Imperador. Outro detalhe dessa foto que chama a atenção é que D. Pedro II segura uma bengala na mão esquerda, símbolo de status. Já a segunda fotografia lembra muito a pintura pela forma descontraída que o personagem se encontra, pois está sentado com a mão calmamente repousada sobre uma escrivaninha. É provável que as fotografias tenham servido de inspiração ao pintor, além disso, na fala de Weingärtner, que veremos abaixo, fica clara a intenção da utilização do retrato do Imperador para fins de sociabilidade do artista:

\footnotetext{
${ }^{5}$ PACHECO, Joaquim Insley. Pedro II, Imperador do Brasil: retrato, 1883. Acervo FBN.

${ }^{6}$ HENSCHEL, Alberto. Dom Pedro II, Rio de Janeiro. 1875. Coleção Waldyr da Fontoura Cordovil Pires.
} 
Tomei a liberdade de pintar um retrato a óleo de Vossa Majestade Imperial, baseado em um cartão fotográfico de Alberto Henschel da Corte, e também do Exmo. Vosso Conselheiro D’Ávila, atual ministro da agricultura para mostrar o progresso que fiz, sendo aliás bastante difícil sem a presença da pessoa o que pode ter dado lugar a erros graves, a respeito das cores e da semelhança (TARASANTCHI, 2009, p. 153).

Esse trecho da carta que foi enviada ao Imperador possibilita observar o modo que Weingärtner claramente utilizou da elaboração do retrato, o qual presenteou o Imperador e o seu Ministro como forma de sustentar a boa relação, mostrar o progresso artístico, e manter a bolsa, além, obviamente, de demonstrar gratidão àquele que lhe financiou seus estudos. Nesse caso, portanto, o retrato tanto do Imperador quanto de seu Ministro, foram formas de firmar laços sociais.

Tanto o retrato de Júlio de Castilhos quanto D. Pedro II são representações de grandes líderes políticos brasileiros e mostram a relevância de Pedro Weingärtner para a sociedade, uma vez que mantinha fortes laços com a aristocracia brasileira, sendo considerado o "pintor da pátria" no Brasil do século XIX. Os retratos no contexto da elite brasileira, no século XIX, podem ser entendidos como valiosos instrumentos de análise; como parte de um jogo de poder de distinção social. Busca-se marcar o poder, a respeitabilidade e o privilégio por meio das imagens. A pintura de retrato funcionava como uma forma de eternização da memória iconográfica dos personagens que, em diferentes épocas, passaram pelas telas do pintor. Os retratos da elite no Brasil também se configuram como locais de disputa de poder e podem ser compreendidos dentro desse contexto:

Os estudos sobre as elites brasileiras mostram a importância do
pertencimento desse grupo nas instituições conferidoras de poder e status. No
Brasil, no decorrer dos tempos, dentre as estratégias de manutenção do poder
local das famílias proprietárias ou de elites destacam-se a grande propriedade
de terras, casamentos endogâmicos e prole numerosa, ao lado da ocupação
dos cargos chaves nas administrações municipais, regionais e, muitas vezes,
nacionais. Esse conjunto de fatores possibilitou a construção de toda uma
rede de poder local [...] (BILAC, 2014, p. 334).

Ao tratar essa relação de poder entre as elites brasileiras, observa-se a importância da construção de um imaginário social. Definindo o imaginário, Sandra Pesavento (1995), o trata como um aspecto que tem ganhado grande espaço nos estudos históricos nas últimas décadas. E, portanto, o imaginário seria uma representação a qual Pesavento chama de "jogo de espelhos", onde o real e o imaginário se confundem:

O imaginário é, pois, representação, evocação, simulação, sentido e significado, jogo de espelhos onde o "verdadeiro" e o aparente se mesclam, estranha composição onde a metade visível evoca qualquer coisa de ausente e 
difícil de perceber. Persegui-lo como objeto de estudo é desvendar um segredo, é buscar um significado oculto, encontrar a chave para desfazer a representação do ser e parecer (PESAVENTO, 1995, p. 24).

Sobre a relação entre a memória e o imaginário social, este seria um território complexo de percorrer. Márcia Janete Espig (2008) aponta a importância do imaginário na funcionalidade da sociedade: "Os imaginários sociais proporcionam a um grupo a designação de uma identidade e de uma representação sobre si próprio, auxiliando ainda na distribuição de papéis e funções sociais, expressão de crenças comuns e modelos" (ESPIG, 2008, p. 54). Os símbolos que as imagens carregam precisam ser reconhecidos e percebidos pelos seus espectadores para que os mesmos possam construir os imaginários sociais. Esses elementos aparecem abundantemente nas pinturas do século XIX, por meio de joias, roupas, móveis, condecorações, espadas, uniformes, posturas e demais itens que são construtores de determinadas imagens e memórias.

Nesse sentido, a elite brasileira necessitava da produção de signos e símbolos de diferenciação para compor um corpus elitista que se distinguisse dos demais e que demarcasse de vez seus lugares na sociedade. Os retratos são os portadores desses símbolos e signos. É relevante ainda afirmar que a elaboração de retratos permitiu ir além da visibilidade social: "[...] se por um lado os retratos permitem uma compreensão mais nítida das redes informais de poder das elites brasileiras, por outro oferecem um registro e uma representação da autoimagem desse grupo dirigente em fases de afirmação social" (BILAC, 2014, p. 334).

Os retratos que Pedro Weingärtner elaborava são importantes fontes que apresentam seus laços de amizade. Agraciar essas pessoas com seus retratos e de respectivos familiares era uma forma de retribuição e de reconhecimento pelo mecenato, além de ser uma demonstração de amizade, uma vez que constituía laços e redes sociais importantes para sua carreira. Dentre os muitos tipos que Weingärtner pintou, destacamse a figura de Henrique d’Avila, Dr. Carlos Wallau e seu filho. Ainda no ano de 1887, com o auxílio de Carlos von Koseritz, Weingärtner consegue uma bolsa para retornar por seis meses ao Brasil e, em dezembro do mesmo ano, fez os retratos de Carlota e Adelaide Koseritz, possivelmente como um gesto de agradecimento pela intervenção e ajuda do amigo ${ }^{7}$. Outros companheiros que tiveram seus retratos produzidos foram o

\footnotetext{
${ }^{7}$ Carlos von Koseritz, um político atuante no que concerne à vida do imigrante alemão no Brasil, almejou a integração deste ao projeto nacional, conforme: "Koseritz defendia princípios liberais, que se manifestavam no campo filosófico, literário, religioso, político e econômico. De maneira incisiva tornouse porta-voz dos projetos e necessidades dos imigrantes alemães e de seus descendentes no Rio Grande do
} 
Dr. Carlos Magalhães de Azeredo e o Dr. Bruno Chaves, este médico em Pelotas e que foi também embaixador em Roma, no ano de 1899. Sobre as pinturas de retrato de Weingärtner, Ângelo Guido discorre: "É o aspecto menos conhecido da sua obra, pois raramente Weingärtner expunha os retratos que pintava, embora em todas as fases da sua evolução artística, desde que em Munique executou os primeiros quadros tenha tido encomenda de retratos" (GUIDO, 1956, p. 83). O fato de não expor seus retratos ainda pode decorrer da função de que possivelmente serviriam para presentear o personagem retratado e não para exposição e venda como foi o caso de outros quadros de gênero do artista, exceto quando eram encomendados ${ }^{8}$.

Abaixo, segue a figura 5, o retrato da senhora Bruno Toledo, de 1917, uma imagem bastante delicada e abundante em detalhes. Observa-se a personagem sentada com um delicado vestido branco, contendo rendas e babados, e com uma longa fita preta que se destaca na roupa, juntamente com as meias e o sapato preto. A moça está sentada ao lado de sua harpa com os cabelos presos em um coque. O cenário é bastante colorido, e demonstra em todos os detalhes da decoração o poder aquisitivo da senhora, observando os finos móveis, cadeiras, tapetes e vasos. O cenário interno identifica uma morada de alta classe. A cena está ornamentada por uma grande variedade de plantas e flores. Embora não tenham sido encontrados grandes informações sobre a retratada, apenas pode-se inferir, observando a imagem, que se trata de uma moça da alta classe brasileira. Além disso, a tela é marcada por elementos delicados e femininos, tal qual a senhora representada.

Sul, valendo-se da imprensa como instrumento de divulgação e alargamento do seu ideário" (WEIZENMANN, 2012, p. 662).

8 Atenta-se que os retratos também possuíam um importante valor mercadológico, pois eles eram a principal fonte de renda da maioria dos artistas do século XIX. 


\section{Figura 5 - Senhora Bruno Toledo}

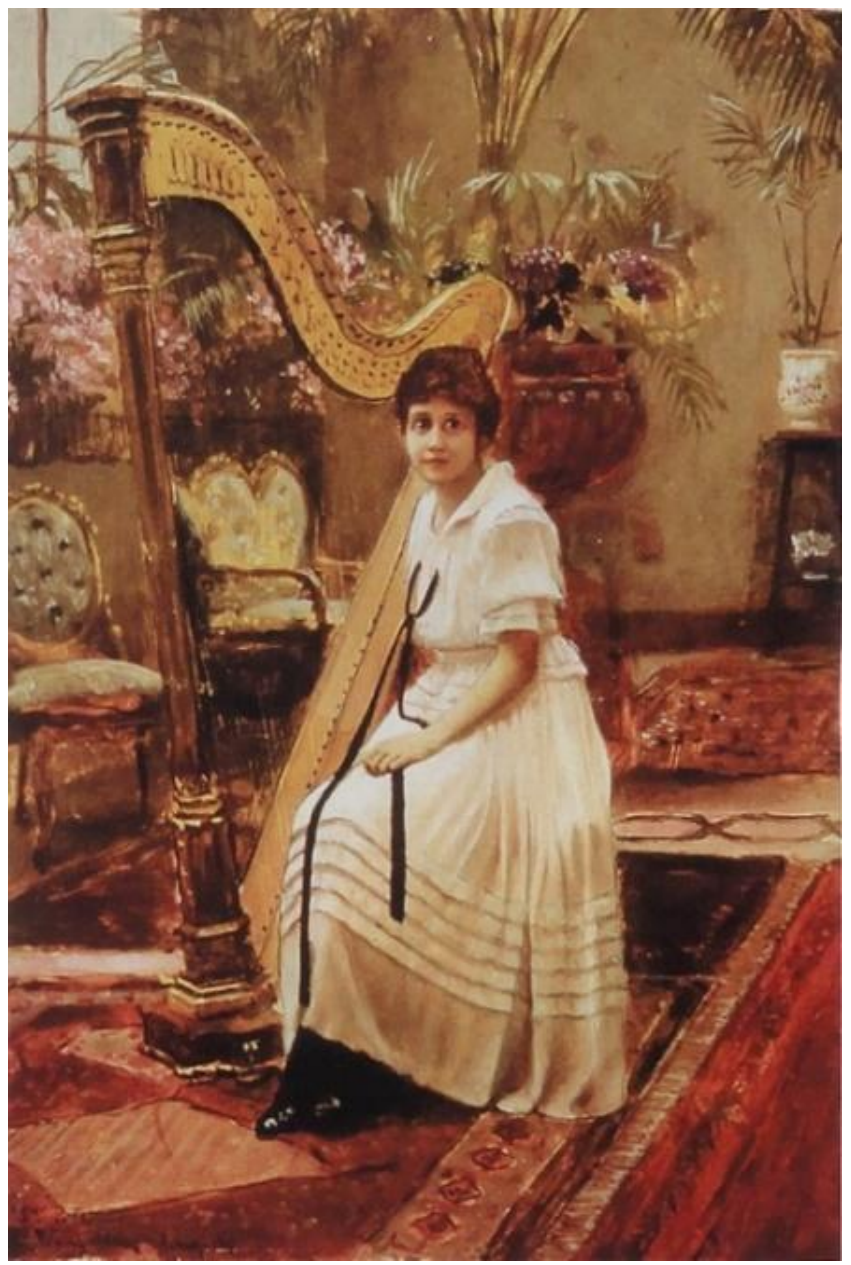

Fonte: (WEINGÄRTNER, 1917). ${ }^{9}$

A figura 6, de Carlos Magalhães de Azeredo, foi pintada em 1903. Weingärtner representou um diplomata brasileiro que residia em Roma. Azeredo foi membro do Instituto Histórico e Geográfico Brasileiro, da Academia Internacional de Diplomacia e do Instituto de Coimbra. Seus primeiros estudos foram realizados no Porto e após formar-se, ele retorna ao Brasil, onde passou a escrever poemas e outros temas literários. Formou-se em Direito e ingressou na carreira diplomática. Devido à sua profissão, passou parte de sua carreira tendo residência em Roma, pois atuava junto ao Vaticano (COUTINHO, 1961). É relevante atentar que Pedro Weingärtner possuía também ateliê em Roma, sendo provável que os dois tenham estabelecido laços de amizade e solidariedade em função da aproximação geográfica e linguística. Nos relatos de Guido, encontramos informações de que teriam sido amigos íntimos. O retrato seria

\footnotetext{
${ }^{9}$ WEINGÄRTNER, Pedro. Retrato da Senhora Bruno Toledo, óleo sobre tela, 23,5 x $16 \mathrm{~cm}$, coleção particular, 1917, Porto Alegre, RS.
} 
apenas um elemento indicador do fortalecimento da relação entre o pintor com o diplomata e a sua respectiva família. Nesse caso, atenta-se que as pinturas de Weingärtner ultrapassaram as fronteiras nacionais, não apenas nas exposições que fez na Europa quando residia por lá, mas também em virtude de retratar membros da elite social e política que viviam no Velho Continente, tornando significativa a circularidade de suas pinturas, como no caso desse retrato pintado e exposto em Roma.

\section{Figura 6 - Carlos Magalhães de Azeredo}

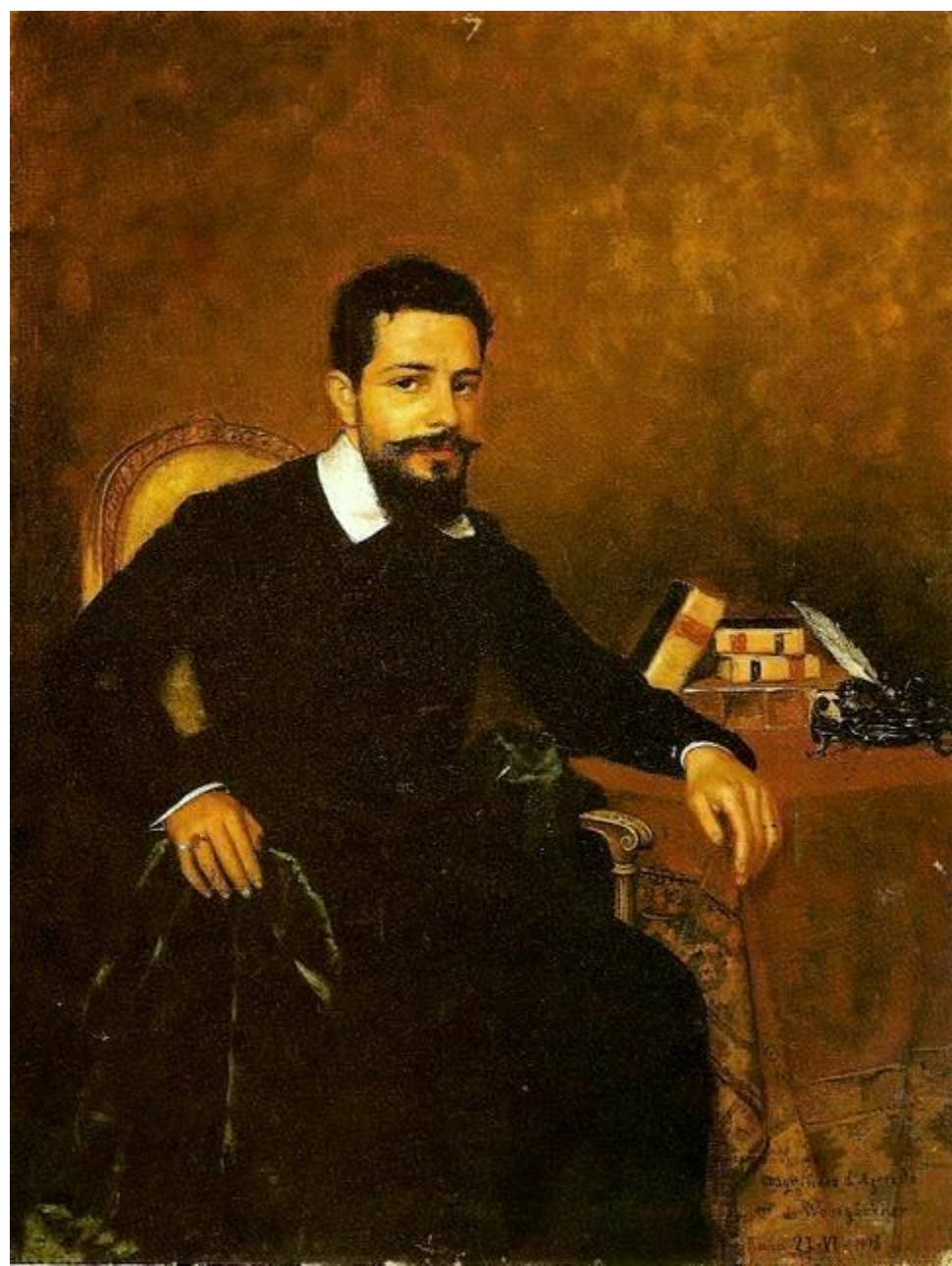

Fonte: (WEINGÄRTNER, 1903). ${ }^{10}$

A representação de Azeredo confere o status intelectual de escritor e diplomata do retratado. A sua figura foi reproduzida sentada ao lado de uma escrivaninha, que está coberta com uma fina toalha e traz em cima dela uma pilha de livros e uma pena de escrever, esta como símbolo da vida letrada que o personagem levava. O retrato busca

\footnotetext{
${ }^{10}$ WEINGÄRTNER, Pedro. Retrato do Embaixador Carlos Magalhães de Azeredo. 1903, óleo sobre tela, $32.5 \times 24.5 \mathrm{~cm}$.
} 
representar o personagem dando destaque aos elementos de sua profissão, como também traz na mão direita um ano de pedra vermelha, símbolo do bacharel, dos estudos e de sua formação. As vestes escuras e elegantes conferem um ar de aristocracia a Azeredo. Atenta-se ainda que, em 1899, Weingärtner teria feito um retrato da esposa do embaixador, informações que encontramos em Molina, (2014, p. 111). Ao que tudo indica, por meio da leitura da biografia escrita por Ângelo Guido, localizamos alguns relatos de que Weingärtner viria a ser um amigo íntimo de Azeredo, pois:

[...] Pelo que se pode deduzir de vários cadernos que examinamos, não viajava nunca, não realizava mesmo um passeio, como os que fazia, aos domingos, em geral, em companhia do íntimo amigo Carlos Magalhães de Azeredo, então cônsul em Roma, sem levar o seu pequeno caderno em que ia anotando o que lhe interessava ou podia servir-lhe para uma composição. E os desenhos miúdos, cuidados ou rápidos, mas sempre reveladores de perícia surpreendente e da elegância conquistada pelo seu traço, iam enchendo páginas e páginas, constituindo um dos aspectos da sua obra sumamente interessante, não só pelo que nos revela do seu valor como desenhista, como observador agudo e estudioso apaixonado do conteúdo estético das coisas, mas também pelo que documenta relativamente aos seus processos de trabalho, ao cuidado e honestidade com que era a sua obra de arte elaborada (GUIDO, 1956, p. 75-76).

Em um outro momento, Guido nos apresenta um relato escrito, em artigo elaborado pelo próprio Azeredo sobre o pintor, no qual fica bem clara a amizade e o carinho que ele nutria pelo artista. $O$ texto de Azeredo exalta não apenas a qualidade da arte de Weingärtner, mas demonstra o quanto o embaixador conhecia o amigo, revelando detalhes do seu modo de pintar e de seus hábitos cotidianos, mas especialmente engrandecendo sua personalidade nas linhas que escreveu. Não à toa, Weingärtner teria retribuído essa amizade retratando tanto Azeredo como sua esposa. É necessário observar que, mais uma vez, o artista utilizou de sua arte na elaboração e nos retratos como forma de demonstração de afeto, gratidão e manutenção das redes sociais. Guido transcreve a seguinte fala do artigo escrito por Azeredo:

[...] Então, trabalha-se muito? - É claro que sim, êle não conhece a preguiça, e, embora eu o suspeite, por aqueles seus olhinhos azuis velados de brumas tudescas, de ser grande sonhador, certamente êle, com sabedoria, reserva para as vagas, indolentes contemplações as horas do crepúsculo e da noite... em que não há luz para pintar!

Dias inteiros passa diante do cavalete, traçando um esboço ou acuradamente adiantando um quadro, em face dos modelos dispostos com harmonia para uma pastoral grega ou uma orgia pompeana, levantando-se de longe em longe para corrigir uma atitude, combinam melhor as dobras de um peplo ou de um pálio, detendo-se um minuto, à conveniente distância, para observar uma côr, uma sombra.... O silêncio não lhe pesa, porque o pincel nas suas mãos fala mais e melhor que a língua. Se algum amigo aparece, também nada lhe custa ouvir e conversar, sem interromper por isso o trabalho. Weingärtner, 
expansivo como poucos, não é tagarela como ninguém; sobretudo não faz frases, não tem sombra da facúndia e do pedantismo de certos artistas, cujo prazer ingênuo consiste muitas vezes em estragar obras claras com teorias obscuras. Não lhe peçam doutrinas, nem declamações; belas ideias sim, e especialmente belos quadros. A sua linguagem é como a sua alma, de uma limpidez de água corrente; água corrente que tem, aliás, quanto à vontade, a força tenaz e constante de um rio" (GUIDO, 1956, p. 76-77).

Outro retrato importante, mas que infelizmente não foi possível localizar a imagem, seria o do Doutor Bruno Chaves, em 1899, e da sua esposa. Ambos foram elaborados no mesmo ano por Weingärtner (MOLINA, 2014, p. 111). Outro indicativo da boa relação que o artista possuía com o alto escalão político brasileiro no exterior seria o seguinte trecho encontrado em João Moreira de Araripe Macedo:

\begin{abstract}
Naquelle importante estabelecimento de instrucção teve como primeiro professor de desenho Pedro Weingartner, distincto pintor Sul-Rio-Grandense, que conheci em Roma nos salões de Bruno Chaves, Ministro Brasileiro junto ao Vaticano, em uma soirée de recepção dada por esse ¡Ilustre diplomata em homenagem a D. Duarte Leopoldo, que acabava de ser sagrado Bispo do Paraná (MACEDO, 1877, s/p).
\end{abstract}

\title{
Considerações finais
}

Os valores simbólicos presentes nos retratos revelam formas de estratégia de representações de diferentes grupos. Isso serve também na política, como no caso do retrato de Júlio de Castilhos, cheio de símbolos que representam a ordem como a assinatura da Constituição. Já a elite local, que busca mostrar o seu status, e, para isso, utiliza-se de símbolos e signos dentro e fora do seu ambiente doméstico, conforme o intuito do retratado (BOHNS, 2005, p. 56). Sobre a importância da utilização dos retratos no Rio Grande do Sul, compreende-se que: “O retrato pintado serviu [...] como instrumento para a promoção social não só da pessoa retratada, como daqueles que, eventualmente, se empenhavam em encomendar a tela ao pintor, e depois em oferecê-la ao ilustre dignitário que merecera tal homenagem" (BOHNS, 2005, p. 57).

A ligação de Weingärtner com a elite é significativa no sentido de apontar sua participação na produção de uma memória dessa elite nacional, seja ela política ou não ${ }^{11}$. Considerando que os periódicos divulgariam os retratados, quem encomendou o retratista, pode-se afirmar que esse tipo de pintura era também uma forma de divulgação dos trabalhos e talentos artísticos do período. Os retratos possibilitavam uma

\footnotetext{
${ }^{11}$ No entanto, há também os que fizeram o retrato do pintor, como Augusto Luiz de Freitas, e Henrique Bernardelli, sendo isso um forte indício do status que Weingärtner adquiriu ao longo de sua trajetória Henrique Bernadelli, em 1894, elaborou uma caricatura de Weingärtner, no qual ele destaca o pintor pela sua profissão.
} 
visibilidade social e de ostentar poder e status no final do século XIX. Também se configuravam como formas de representação de uma presença simbólica em locais de destaque na sociedade. Nesse sentido, pode-se dizer que Pedro Weingärtner teve sua presença simbólica na sociedade brasileira. No momento em que ganhou destaque nas páginas dos jornais por meio de imagens que o representavam e que contavam um pouco de sua trajetória, ao menos no âmbito profissional, confirmava-se seu status no Brasil. Além disso, foi importante os retratos que o pintor elaborou, pois, considerado um dos mais destacados artistas do século XIX, ele pôde ajudar a construir a imagem da elite social e política brasileira.

\section{REFERÊNCIAS}

AGUILAR, Nelson. Mostra do Redescobrimento: Arte do século XIX - 19th-Century Art. São Paulo: Fundação Bienal de São Paulo, 2000.

BAXANDALL, Michael. Padrões de intenção: a explicação histórica dos quadros. São Paulo: Companhia das Letras, 2006.

BILAC, Maria Beatriz Bianchini. Elites e retratos: um estudo sobre as galerias de honra das misericórdias de São Paulo e Santos. ACERVO, Rio de Janeiro, v. 27, n. 1, p. 333$348,2014$.

BOHNS, Neiva Maria Fonseca. Continente Improvável: Artes Visuais no Rio Grande do Sul do final do século XIX a meados do século XX. 2005. 383 f. Tese (Doutorado em Artes Visuais). Programa de Pós-Graduação em Artes Visuais, Universidade Federal do Rio Grande do Sul - UFRGS, Porto Alegre, RS, 2005.

BORGES, Luiz Carlos; BOTELHO, Marília Braz. Positivismo e artes plásticas: O Museu Nacional e a I Exposição Antropológica Brasileira (1882). Disponível em: <http://hdl.handle.net/123456789/2093> Acesso em 24 de set. 2016.

CHARTIER, Roger. Por uma sociologia histórica das práticas culturais. A História Cultural - entre práticas e representações. Lisboa: DIFEL, 1990.

COMISSOLI, Adriano; COSTA, Miguel Ângelo Silva da. Estrelas de primeira grandeza: reflexões sobre o uso de redes sociais na investigação histórica. MÉTIS história \& cultura, v. 13, n. 25, p. 11-30, 2014.

COUTINHO, Afrânio. Brasil e brasileiros de hoje. Rio de Janeiro: Sul Americana, 1961.

ESPING, Márcia Janete. O conceito de imaginário: Reflexões acerca de sua utilização pela História. Textura, Canoas, v. 5, n. 9, p. 49-56, 2013. 
FERREIRA, Cláudio Barcellos Jansen; ROSSI, Elvio Antônio; KAMPMANN, Helen Bertoletti; SILVA, Marcelo de Souza; FROZZA, Marilia de Oliveira. A retratística e a família na arte brasileira, séculos XIX e XX. 19\&20, Rio de Janeiro, v. VIII, n. 2, 2013.

GOMES, Paulo. Artes Plásticas no Rio Grande do Sul: uma Panorâmica. Porto Alegre: Lahtu Sensu, 2007.

GUIDO, Ângelo. Pedro Weingärtner. Porto Alegre: Divisão de Cultura - Diretoria de Artes da Secretaria de Educação e Cultura, 1956.

MACEDO, João Moreira de Araripe. Diccionario Bio-bibliographico Cearense Barão de Studart. $1987 . \quad$ Disponível em: <http://ceara.pro.br/cearenses/listapornomedetalhe.php?pid=32051> Acesso em 25 de set. 2016.

MOLINA, Lucas Giehl. O universal, o local e a memória cultural na obra de Pedro Weingärtner (1853-1929). 2014. 124f. Dissertação (Mestrado em História) Universidade Federal do Rio Grande do Sul, Instituto de Filosofia e Ciências Humanas, Programa de Pós-Graduação em História, Porto Alegre, 2014.

NORA, Pierre. Entre Memória e História: a problemática dos lugares. Projeto História. São Paulo: PUC, v.10, n. 10, p. 07-28, 1993.

PESAVENTO, Sandra Jatahy. Em busca de uma outra História: imaginando o imaginário. Revista Brasileira de História, São Paulo, v. 15, n. 29, p. 9-27, 1995.

RODRÍGUEZ, Antonio Acosta. las redes socialies, el poder y sus fundamentos. Anuario IEHS, Tandil, n. 15, p. 153-171, 2000.

SILVA, Ana Celina F. O Museu e a consagração da memória de Júlio de Castilhos. 2011. 58 f. Trabalho de Conclusão de curso (Bacharel em Museologia) - Universidade Federal do Rio Grande do Sul, Faculdade de Biblioteconomia e Comunicação, Porto Alegre, 2011.

TARASANTCHI, Ruth Sprung. Pedro Weingärtner (1853-1929): um artista entre o Velho e o Novo Mundo. São Paulo: Pinacoteca do Estado de São Paulo, 2009.

WEIZENMANN, Tiago. Karl von Koseritz e o debate cientificista: uma perspectiva sobre o evolucionismo na segunda metade do dezenove brasileiro. XI ENCONTRO ESTADUAL DE HISTÓRIA. 2012, Rio Grande. Anais... FURG, 2012. p. 661-676. 